\title{
Stressors in intensive care units: strategies for humanization of care
}

\begin{abstract}
Objective: To identify and stratify ICU stressors from the perspective of the patient, comparing stress among different clinics, as well as listing actions that can minimize such factors.

Methods: A descriptive, cross-sectional study was carried out in the clinical and postoperative intensive care units (neurosurgical, cardiovascular and general) of a public hospital. Sixty patients from these units participated. For the identification and stratification of these stressors, the scale of stressors in an intensive care unit was used. The mean score of each item on the scale was calculated and then the total stress score. After the comparison between the groups, the differences were considered significant when $\mathrm{p}<0.05$.

Results: The mean age of patients in the ICU-OP was $54.68 \pm 15.47$ years and the ICU-Clinic was $56.54 \pm 21.31$ years $(\mathrm{p}=0.596)$. Patient groups were similar in terms of demographic and clinical characteristics. The 15 most stressful factors were listed, among them "feeling pain" was the most stressful and "thirst" was the only one that presented a statistically significant difference, in which ICU-OP patients reported being more stressful. The mean TEE in the ICU-OP was $81.06 \pm 18.94$ and in the ICU-Clinic it was $75.61 \pm 15.33$, and there was no statistically significant difference between the ICUs evaluated $(\mathrm{p}=0.419)$. In the comparison between the POI ICUs, the cardiovascular unit reported greater stress related to the environment and the team $(\mathrm{p}=0.031)$. Conclusion: Through simple and low-cost strategies it is possible to minimize the discomfort reported by the patients, making hospitalization a smoother process.
\end{abstract}

Keywords: humanization of care, intensive care unit, critical care
Volume 2 Issue 6 - 2018

\author{
Jenniffer Kelly Assis de Barros, 'Andressa \\ Siuves ${ }^{2}$ \\ 'Resident Nurse, Intensive Care of the Santa Casa Hospital of \\ Belo Horizonte, Brazil \\ ${ }^{2}$ Nurse Intensivist, Preceptor of the Multiprofessional Residence, \\ Santa Casa Hospital of Belo Horizonte, Brazil
}

Correspondence: Jenniffer Kelly Assis de Barros, Resident Nurse in Intensive Care of the Santa Casa Hospital of Belo Horizonte, Brazil, Email jenneffer.kelly@gmail.com

Received: January 12, 2018 | Published: December 12, 2018

\section{Introduction}

Hospitalization causes withdrawal from the family and is permeated by painful and/or uncomfortable procedures. This condition, coupled with the process of illness, favors stress in this environment. ${ }^{1}$

For Cheregatti \& Amorin ${ }^{2}$ this circumstance can be exacerbated if the patient's clinical condition suggests admission to the ICU, since at the same time that it provides integral care of high complexity to the severe individual, it generates stress in the patient due to "physical discomfort and psychological disturbance caused by physical structure, equipment, alarms, noise, intense luminosity, great movement of people, withdrawal from their environment, confrontation with their own suffering and the other and the possibility of death".

Thus, stress can be understood as not adapting the individual to a state of permanent imbalance. The response to stress is a physiological condition, where chemical and electrical reactions of the nervous system trigger a series of organic signals that reveal this exposure, such as elevated blood pressure, increased glucose, cold skin, palpitations among others. prolonged exposure to stressors (stimuli) increases the possibility of disease development. ${ }^{3}$

The changes generated by stressors can influence the therapeutic proposal for the patients, the process of ventilatory weaning ${ }^{4,5}$ and even show the consequences of stress after hospital discharge.

A study conducted by Vesz ${ }^{6}$ evaluated functional and psychological aspects immediately after hospital discharge generating in individuals a high incidence of depressive symptoms, anxiety and sleep disorders in individuals with a stay of 72 hours or more in the ICU.
Psychological stressors such as sleep deprivation, loneliness, fear and anxiety, besides the feeling of submission to health professionals, family affliction, depersonalization and insecurity, can generate anxiety and agony. ${ }^{7}$ These stressors are perceived individually according to the context they present, so from their identification it is possible to act on these factors, adopting measures to promote the humanization of care. ${ }^{8}$

The growing concern about the quality of life of the hospitalized individual has increased the investigations in this area and, currently, there have been changes regarding the dynamics of treatment, consonant with the tendency of humanization practices in health care. ${ }^{9}$

These practices are based on the National Program for Humanization of Hospital Assistance (PNHAH), whose objectives are: to improve hospital structure and dynamics, as well as to promote the educational training of professionals in the area in relation to enhancement and respect for the hospitalized human being ( Page 6 Corroborating this data Mangiovi et al..$^{10}$ maintains that humanization in the hospital environment stands out for providing the incorporation of health relationships, continuously seeking improvements in care and an ideal environment for the development of the same, aiming at valuing the autonomy of the subject and the protagonism in its treatment.

In addition, several studies identifying and stratifying the stressors have been performed, ${ }^{11,12}$ but few have compared such perception in patients with different clinical conditions and proposes an instrument for the systematization of humanized care.

In this context, considering the study by Bianficore et al. ${ }^{13}$ it 
was shown that perceptions of stress factors may vary according to the patient's clinical profile, the impact on the patient's health, the constant presence of stressors in the ICU and interventions will promote a better adaptation of the patient to the environment, the evaluation of stressors becomes a worldwide challenge.

In view of the above, this research intends to evaluate if there are relevant differences between patients from different clinics and proposes to offer through the literature, subsidies for professionals to optimize their knowledge, providing the improvement of clinical practice and humanized and individualized assistance to patients in the intensive care setting.

\section{Methodology}

This is a cross-sectional descriptive study that was developed in the coronary intensive care units, general postoperative, neurosurgical and clinical treatment of a large hospital in Belo Horizonte / MG, in the period of December 2015.

In this period, the ICU had 60 beds for adult patients, 20 beds for clinical treatment and 40 beds for postoperative treatment, divided into 10 for neurosurgical, 10 for cardiovascular and 20 for general postoperative. The study was approved by the Ethics Committee in Research of the Institute of Education and Research of the institution in question under CAEE: 51514415.8.0000.5138.

The sample included individuals of both sexes, aged over 18 years, conscious in Glasgow 15/15, with no history of previous ICU admission, with an ICU stay of at least 24 hours, breathing spontaneously and who agreed in signing the Free and Informed Consent Form (TCLE). Patients who did not present effective verbal communication after applying the Glasgow Coma Scale and those who did not or did not respond well to the questionnaire questions were excluded.

Firstly, the Glasgow coma scale was applied to patients. The patient was asked to provide full name, age, the respective day, the place where he/she was, and evaluation of eye movement and opening. The required score was 15 by 15 points. Afterwards, a sample characterization form elaborated by the authors was used, containing sociodemographic data such as gender, age, schooling and religion.

Acute Physiology and Chronic Health Evaluation II (APACHE II) was the clinical data collected from the medical records, clinical diagnosis, length of ICU stay, identification of equipment and assistance devices used during hospitalization, and data needed to calculate severity scores. The APACHE II score was used for risk and prognostic stratification in ICU patients, and the higher the score, the greater the severity. ${ }^{14}$

The Stressor Questionnaire (ESQ), in its version validated and culturally adapted to the Portuguese language of Brazil, was used to verify stressors. It is called the Stress Evaluation Scale for Intensive Care Units. ${ }^{7}$ The same was applied by the previously trained principal investigator (ANNEX B).

The scale is composed of 50 items to identify the main situations perceived as stressors for the patient. It is subdivided into five domains analyzed based on a specific group of items on the scale: related to the biological dimension (fourteen items), psychological (thirteen items), (nine items), the psychosocial and affective dimension (seven items) and unpredictability and impersonality (seven items).

The stress level of each item is determined by a scale from zero to 4 , being considered value 1 as non-stressful, 2 slightly stressful, 3 stressful, 4 very stressful and zero not applicable, if the patient has not experienced the stressful event. The variability of the score in this scale ranges from zero to 200 , and the higher the value, the greater the perceived stress of the patient.

Statistical Package for Social Science (SPSS) 23.0 was used to analyze the data. The information obtained was exposed in absolute values, percentage, median or as mean \pm standard deviation. Initially, the Shapiro-Wilk and Kolmogorov-smirnov tests were applied to verify the normality of the data. Comparison of sociodemographic and clinical data among ICUs was performed using Student's t test, chi-square, Fisher's exact test.

The comparison between the stressors of the ICUs was performed using the $\mathrm{U}$ test of Mann Whitney and $\mathrm{H}$ of Kruskal-wallis. All inferential tests were used according to the criteria for the same. The Spearman correlation test was used to correlate the clinical variables with the total stress score (TEE). The level of significance was accepted when $\mathrm{p}<0.05$ and $95 \%$ confidence interval.

\section{Results}

After selecting patients eligible for the study, three patients were excluded because they chose not to answer the questionnaire. Thus, 60 patients participated in the study, being 47 individuals from the surgical ICU and 13 from the clinical ICU.

The mean age of patients in the ICU-OP was $54.68 \pm 15.47$ years and the ICU-Clinic was $56.54 \pm 21.31$ years $(\mathrm{p}=0.596)$. Patient groups were homogeneous with regard to the demographic and clinical characteristics evaluated (Table 1).

The mean TEE in the ICU-OP was $81.06 \pm 18.94$ and in the ICUClinic it was $75.61 \pm 15.33$, and there was no statistically significant difference between the ICUs evaluated $(\mathrm{p}=0.419)$. Table 2 presents the main stressors for both ICUs, which will be used to list actions to minimize them.

Regarding the comparison by stressors between the main ones cited by the patients, there was a statistically significant difference between only one item. "Being thirsty" was more stressful for the ICU-OP than for the ICU-Clinic $(\mathrm{p}=0.014)$.

Regarding the APACHE II severity score of the patients evaluated in the OP ICU, this was $12.72 \pm 4.30$, characterizing a sample with a risk of mild to moderate mortality and there was no correlation with the TEE $(p=0.353)$ and in the ICU-clinic was $19.31 \pm 4.40$ and there was also no correlation with the TEE $(\mathrm{p}=0.859)$. Although no statistically significant difference was found, the stressor "being punctured by needles" had a higher mean in the clinical ICU (3.08 $( \pm 1.04))$ than in the OP ICU $(2.59 \pm 1.13)$.

In the investigation of the groups of the ICU-OP, it was found that there was no significant correlation between TEE and variables, age $(p=0.185)$, schooling (years $)(p=0.234)$, gender $(p=0.617)$ and hospitalization $(p=0.263)$. The TEE in the ICU-Clinic also showed no significant correlation with the variables, age $(\mathrm{p}=0.648)$, schooling (years) $(p=0,153)$, gender $(p=0,617)$ and length of hospital stay $(\mathrm{p}=0,506)$.

The fifteen main stressors, in the perception of both ICUs, followed by the mean score and standard deviation, respectively, were: "feeling pain" (2.71 \pm 1.19$)$; "Being punctured by needles" $(2.68 \pm 1.11)$; "Being afraid of getting AIDS" (2.66 \pm 0.98$)$; "Thirst" (2.61 \pm 1.13$)$; "Seeing family and friends only a few moments a day" (2.53 \pm 1.09$)$; "Not having privacy" (2.46 \pm 1.09$)$; "Not having self-control" (2.45 \pm 1.03$)$; "Not knowing what time it is" (2.41 \pm 0.99$)$; "To be incapacitated to

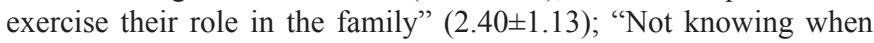


the procedures will be done on you" (2.28 \pm 0.98$)$; "Not knowing the length of ICU stay" (2.25 \pm 0.98$)$; "Have financial concerns" (2.18 \pm 1.06$)$; "Unable to sleep" $(2.15 \pm 1.37)$; "listening for the heart rate monitor to fire" $(2.15 \pm 1.00)$; "Listen to the noise and alarm of the devices" $(2.11 \pm 1.04)$.

Table I Demographic and clinical characteristics

\begin{tabular}{|c|c|c|c|}
\hline \multirow[t]{2}{*}{ Characteristics } & \multirow{2}{*}{$\begin{array}{l}\text { CTI-PO } \\
\mathrm{N}=47\end{array}$} & \multirow{2}{*}{$\begin{array}{l}\text { CTI Clinic } \\
\mathrm{N}=13\end{array}$} & \multirow[t]{2}{*}{$\mathbf{P}$} \\
\hline & & & \\
\hline Age (years)* & $54,68( \pm 15,47)$ & $56,54( \pm 2 I, 31)$ & 0,596 \\
\hline Schooling (years of study)* & $7,19( \pm 3,56)$ & $7,69( \pm 4,2 I)$ & 0,716 \\
\hline \multicolumn{4}{|l|}{ Genre** } \\
\hline Male & $18(38,3)$ & $5(38,5)$ & 0,617 \\
\hline Female & $29(61,7)$ & $8(61,5)$ & 0,617 \\
\hline \multicolumn{4}{|l|}{ Religious Belief** } \\
\hline Yes & $47(100)$ & $13(100)$ & - \\
\hline No & - & - & - \\
\hline \multicolumn{4}{|l|}{ Main devices** } \\
\hline Cardiac monitor & $47(78,3)$ & $13(2 \mid, 7)$ & - \\
\hline Peripheral venous access & $40(85, I)$ & II $(84,6)$ & 0,631 \\
\hline \multicolumn{4}{|l|}{ Main pathologies** } \\
\hline Cardiovascular system & $17(36,2)$ & $6(46,2)$ & - \\
\hline Respiratory system & $3(6,4)$ & $2(15,4)$ & - \\
\hline Gastrointestinal System & $\mathrm{I}(2, \mathrm{I})$ & $2(15,4)$ & - \\
\hline Renal / Metabolic System & $5(10,6)$ & $3(23,1)$ & - \\
\hline Neurological System & $13(27,7)$ & - & - \\
\hline Gastrointestinal Neoplasia & $8(17,0)$ & - & - \\
\hline Length of stay (days) ${ }^{* * * *}$ & $3,00(2,00)$ & $3,00(2,50)$ & 0,585 \\
\hline Total stress score & $81.06( \pm 18,94)$ & $75.6 I( \pm 15,33)$ & 0,419 \\
\hline
\end{tabular}

Source: Prepared by the author

Table 2 Overall score of stressors in the perception of hospitalized patients of intensive care units

\begin{tabular}{ll} 
& UTI \\
& Average \pm Standard deviation \\
\hline Feel pain & $2,7 I \pm I, 19$ \\
Being punctured by needles & $2,68 \pm I, I I$ \\
Being afraid of getting AIDS & $2,66 \pm 0,98$ \\
Be thirsty & $2,61 \pm 1,13$ \\
See family and friends only minutes a day & $2,53 \pm 1,09$ \\
Do not have privacy & $2,46 \pm 1,09$ \\
Not having control of oneself & $2,45 \pm 1,03$ \\
Not knowing what time it is & $2,41 \pm 0,99$ \\
Being unable to play their part in the family & $2,40 \pm 1,13$ \\
Not knowing when the procedures will be done on you & $2,28 \pm 0,98$ \\
Not knowing the length of stay in ICU & $2,25 \pm 0,98$ \\
Have financial worries & $2,18 \pm 1,06$ \\
I can not sleep & $2,15 \pm 1,37$ \\
Listen to the heart monitor alarm shoot & $2,15 \pm 1,00$ \\
Listen to the noise and alarm of the devices & $2,11 \pm 1,04$ \\
\hline
\end{tabular}


In the comparison between the subdivision in domains (domain 1 , $\mathrm{p}=0.196$, domain $2, \mathrm{p}=0.052$, domain $3, \mathrm{p}=0.907$, domain $4, \mathrm{p}=0.850$ and domain $5, \mathrm{p}=0.871$ ), there was no significant statistical difference between ICU-OP and ICU-clinical, however, when comparing the different surgical specialties, there was a significant statistical difference in the team-related and environment-related factors, in which patients in the cardiovascular ICU-OP considered it more stressful $(p=0.031)$ than the other specialties (Table $3 \& 4$ ).

Table 3 Comparison of the stressors score in the patients' perception

\begin{tabular}{|c|c|c|c|c|c|}
\hline Stress Factors & \multicolumn{2}{|c|}{ UTI Surgical Average \pm Standard deviation } & \multicolumn{2}{|c|}{ UTI Clinic Average $\pm S t a n d a r d ~ d e v i a t i o n$} & $\mathbf{P}$ \\
\hline Feel pain & \multicolumn{2}{|l|}{$2,72( \pm I, 17)$} & \multicolumn{2}{|l|}{$2,69( \pm 1,38)$} & 0,888 \\
\hline Being punctured by needles & \multicolumn{2}{|l|}{$2,59( \pm 1,13)$} & \multicolumn{2}{|l|}{$3,08( \pm 1,04)$} & 0,150 \\
\hline Being afraid of getting AIDS & \multicolumn{2}{|l|}{$2,70( \pm 0,96)$} & \multicolumn{2}{|l|}{$2,54( \pm I, I 3)$} & 0,599 \\
\hline Be thirsty & \multicolumn{2}{|l|}{$2,80( \pm 1,07)$} & \multicolumn{2}{|l|}{$1,92( \pm 1,19)$} & 0,014 \\
\hline $\begin{array}{l}\text { See family and friends only } \\
\text { minutes a day }\end{array}$ & \multicolumn{2}{|l|}{$2,61( \pm I, 08)$} & \multicolumn{2}{|l|}{$2,23(1,17)$} & 0,271 \\
\hline Do not have privacy & \multicolumn{2}{|l|}{$2,39( \pm 1,08)$} & \multicolumn{2}{|l|}{$2,69( \pm 1,18)$} & 0,398 \\
\hline Not having control of oneself & \multicolumn{2}{|l|}{$2,48( \pm 1,09)$} & \multicolumn{2}{|l|}{$2,38( \pm 0,87)$} & 0,603 \\
\hline Not knowing what time it is & \multicolumn{2}{|l|}{$2,57( \pm 0,86)$} & \multicolumn{2}{|l|}{$2,08( \pm 1,19)$} & 0,234 \\
\hline $\begin{array}{l}\text { Being unable to play their part in } \\
\text { the family }\end{array}$ & \multicolumn{2}{|l|}{$2,37( \pm I, \mid 4)$} & \multicolumn{2}{|l|}{$2,62( \pm I, I 2)$} & 0,441 \\
\hline $\begin{array}{l}\text { Not knowing when the } \\
\text { procedures will be done on you }\end{array}$ & \multicolumn{2}{|l|}{$2,37( \pm 0,99)$} & \multicolumn{2}{|l|}{ I,92 ( $( \pm, 04)$} & 0,163 \\
\hline $\begin{array}{l}\text { Not knowing the length of stay } \\
\text { in ICU }\end{array}$ & \multicolumn{2}{|l|}{$2,22( \pm I, 05)$} & \multicolumn{2}{|l|}{$2,3 I( \pm I, I I)$} & 0,836 \\
\hline Have financial worries & \multicolumn{2}{|l|}{$2,28( \pm I, I I)$} & \multicolumn{2}{|l|}{$\mathrm{I}, 77( \pm 0,83)$} & 0,102 \\
\hline I can not sleep & \multicolumn{2}{|l|}{$2,17( \pm 1,35)$} & \multicolumn{2}{|l|}{$2,23(1,42)$} & 0,825 \\
\hline $\begin{array}{l}\text { Listen for the alarm of the heart } \\
\text { monitor to shoot }\end{array}$ & \multicolumn{2}{|l|}{$2,17( \pm 1,06)$} & \multicolumn{2}{|l|}{$2,00(0,82)$} & 0,534 \\
\hline $\begin{array}{l}\text { Listen to the noise and alarm of } \\
\text { the devices }\end{array}$ & \multicolumn{2}{|l|}{$2,24( \pm I, 10)$} & \multicolumn{2}{|l|}{$1,69( \pm 0,75)$} & 0,119 \\
\hline \multirow{2}{*}{\multicolumn{2}{|c|}{ Domains stress factors }} & UTI Cardiovascular & UTI Neurosurgical & UTI General Surgical & $\mathbf{P}$ \\
\hline & & Average \pm SD & Average \pm SD & Average \pm SD & \\
\hline Domain I- Related to the biological & imension & $1,95 \pm 0,50$ & $2,20 \pm 0,66$ & $\mathrm{I}, 94 \pm 0,38$ & 0,631 \\
\hline Domain 2- Related to the psycholog & al dimension & $\mathrm{I}, 85 \pm 0,40$ & $\mathrm{I}, 68 \pm 0,49$ & $\mathrm{I}, 70 \pm 0,44$ & 0,390 \\
\hline Domain 3- Related to staff and envir & nment & $1,62 \pm 0,46$ & $1,20 \pm 0,60$ & $\mathrm{I}, 24 \pm 0,50$ & 0,031 \\
\hline $\begin{array}{l}\text { Domain 4-Related to the psychosoc } \\
\text { dimension }\end{array}$ & I and affective & $\mathrm{I}, 15 \pm 0,52$ & $1,12 \pm 0,68$ & I,22 $\pm 0,59$ & 0,718 \\
\hline Domain 5- Related to unpredictabili & and impersonality & $2,13 \pm 0,66$ & $\mathrm{I}, 94 \pm 0,8 \mathrm{I}$ & $\mathrm{I}, 80 \pm 0,57$ & 0,332 \\
\hline
\end{tabular}

SD: Standard Deviation / Source: Prepared by the author

\section{Discussion}

Regarding the results obtained by the present study, it is noteworthy that the patients of both ICUs, even in different clinical conditions presented similar stress levels, which corroborates with the research by Dias et al. ${ }^{15}$ that evaluated 60 patients of clinical characteristics and found no statistically significant relationship between stress levels.

This similarity can be explained by the conformity between the ICUs, both by the organizational operation and by the physical structure, where beds, equipment and furniture are similar. It is worth mentioning that the stress values in the questionnaire vary from 1 (nonstressing) to 4 (very stressful), the patients in the sample considered ICU admission as a little stressful.
Thus, even if there is no statistically significant relationship between the total stress score and the sociodemographic characteristics, this data can be justified by the mean age of the sample 54,68 and 56,54 of the OP and clinical ICU respectively, since according to Marosti $\&$ Dantas $^{16}$ longer-lived patients are conditioned to tolerate some discomforts and inconveniences when hospitalized.

However, there was a significant statistical difference in the comparison of domains among the specialties of the ICU-OP, the cardiovascular specialty even though it was compatible with the general average of the ICU-OP $(56( \pm 14,22))$, considered more stressful domain $3 \mathrm{p}=0.031$ ) that refers to the team and the environment. This domain comprises nine items, of which the items cited by the patients were: "to be frequently examined by medical and 
nursing staff", "to hear people talking about you", "to have strange machines around them".

Since these factors were not the most stressful ones reported by the patients, this finding can be justified by the fact that patients of this specialty in their totality are submitted to intubation and insertion of abdominal drains and bladder catheters, reducing their tolerance to such items.

Another relevant score is that of the main stressors listed only seven are consistent with the literature, where they highlight "seeing family and friends only a few minutes a day", "unable to sleep", "not knowing what time it is", "feeling pain", "Being afraid of getting AIDS", "not having control of oneself", "having financial worries", "being trapped by tubes and drains", "having tubes in the nose and mouth". ${ }^{15}$

It should be noted that the last two stressors mentioned above were not mentioned by the population studied, since the sample consisted of patients who were mostly intubated for a few hours, and/or with drains and oxygen supplementation, or who were not submitted to such procedure, besides not being in use of nasoenterals or gastricos probes.

The main stressing factor pointed out by the patients in the study was "feeling pain", as well as previous research that obtained the same data. ${ }^{15,17}$ Pain is an important factor of suffering, affects the quality of life and compromises the physical and psychosocial state (NASCIMENTO, SILVA 2014). However, his evaluation is too complicated because of his subjective, individual, emotional nature and his peculiarities. ${ }^{18}$

Still, according to Stumm et al. ${ }^{18}$ there is a link between the onset of pain and the onset of pain, the increase in tension manifests itself as pain. Thus, "pain is understood not only as coming from the procedure that the patient is or has undergone, but the whole set of physical and psychological discomforts."

Thus, in the ICU environment, several factors can aggravate this sensation: invasive and painful procedures such as punctures, probing, insertion of drains, frequent examinations, confinement, bed discomfort, family withdrawal, depersonalization among others.

In this context, it is imperative to consider the multidimensionality of pain, providing an effective measurement and interventions to relieve pain, since the ineffectiveness of pain relief coupled with anxiety can generate severe agitation and the accidental removal of the care devices exposing the patient to the risk, aggravating the stressful situation. ${ }^{15}$

Such interventions are part of the care, so it is up to the multiprofessional team to "evaluate pain and commit measures for their relief, providing comfort and well-being to the subject, and can be considered as devices capable of promoting health and humanized care during hospitalization". ${ }^{19}$

Closely related to pain relief is the "needle boring" factor, one of the biggest causes of discomfort to patients in the ICU environment. This is a greater stressor among patients in the clinical ICU than in the postoperative ICU, which can be understood by the fact that patients in the clinical ICU are more frequently submitted to painful invasive procedures than in the OP ICU (eg, gasometry arterial and capillary glycemia).

Therefore, among the actions to minimize this stressor is the individualization of the care where examinations (capillary glycemia, various laboratory tests) and invasive procedures are requested only if and / or when necessary and not allowing care to become plastered and technicist, decreasing critical patient stress.

Among the main stressors only one presented a statistically significant difference, "being thirsty" was pointed out by ICU-OP patients as more stressful than patients in the clinical ICU. This data can be justified by the greater postoperative fasting time in these patients.

Thirst in patients' perceptions generates tremendous stress when they are fasting. Studies have reported that, for them, this results in worsening of anxiety, dehydration, irritability, weakness and despair. ${ }^{20,21}$

According to Oliveira et al. ${ }^{22}$ fasting has an influence on gastrointestinal motility and decreased gastric secretion, acting in the "prevention of complications related to the anesthetic procedure, such as nausea and vomiting in the postoperative period, whose global incidence remains between $20 \%$ and $30 \%{ }^{23}$

However Correia e Silva ${ }^{20}$ report that prolonged fasting from the night before the surgical procedure has been questioned and new behaviors performed, since this practice was initiated when anesthetic techniques were still which significantly increased the possibility of vomiting and, consequently, the risk of aspiration."

In addition, water and other low-calorie liquids (clear liquids such as tea, coffee and pulp-free juices) in healthy patients are known to be readily absorbed. ${ }^{20}$

Therefore, it is understood that the time and need for fasting should be rediscussed and when really needed strategies should be developed to relieve the discomfort caused by thirst. A study conducted by Aroni et al. ${ }^{23}$ in patients in the immediate postoperative period, used thirst measurement methods and offered small amounts of water and ice for the individuals, obtaining a decrease in the intensity of the same.

In another study, the use of moist handkerchiefs on the lips, ice water sprays and lip moisturizers were effective and low cost measures to minimize the stress associated with the thirst of this population. These studies open precedents for further investigations that can understand this problem and propose actions that benefit the patients. ${ }^{24}$

One factor has aroused the interest of the authors, patients have reported being "afraid of getting AIDS," which may demonstrate an unfamiliarity of the sample population about the use of sterile materials in performing invasive procedures, reinforcing the need to provide such information for the individuals in this environment, optimizing the confidence in the assistance provided.

As pain, thirst, and fear can be minimized, there are other modifiable stressors, so it is extremely important that the multidisciplinary team is committed to implementing strategies to minimize them (Table 5). 
Table 5 Multidisciplinary actions to minimize ICU patient stress on modifiable factors

\begin{tabular}{|c|c|c|}
\hline Stress factors & Strategies & References \\
\hline $\begin{array}{l}\text { See family and friends only } \\
\text { minutes a day }\end{array}$ & $\begin{array}{l}\text { Increased length of stay of the family in the ICU environment, facilitating the coping } \\
\text { of the situation lived by the family and patient. }\end{array}$ & Ferreira et al. ${ }^{25}$ \\
\hline Not having control of oneself & $\begin{array}{l}\text { Stimulate the empowerment of the individual, always informing him about the } \\
\text { procedures to be performed, including him in the activities in which he is able to } \\
\text { develop alone or with help, making him feel part of his care. }\end{array}$ & Anvisa ${ }^{26}$ \\
\hline \multicolumn{3}{|l|}{$\begin{array}{l}\text { Not knowing when the } \\
\text { procedures will be done on you }\end{array}$} \\
\hline $\begin{array}{l}\text { Not knowing the length of stay } \\
\text { in ICU }\end{array}$ & $\begin{array}{l}\text { Communicate to the patient daily their evolution, so that the anxiety of not knowing } \\
\text { the date of their discharge is minimized, thus promoting effective communication. }\end{array}$ & Rosa Beatriz Ângelo ${ }^{7}$ \\
\hline Not knowing what time it is & $\begin{array}{l}\text { Possess clocks with date and time, to aid in temporal orientation and sleep-wake } \\
\text { cycles. }\end{array}$ & $\mathrm{Knobel}^{27}$ \\
\hline I can not sleep & $\begin{array}{l}\text { Provide a quiet environment with less light and less noise. Schedule patient-related } \\
\text { procedures and exams with the goal of disrupting sleep as little as possible }\end{array}$ & $\mathrm{Knobel}^{27}$ \\
\hline $\begin{array}{l}\text { Listen to the heart monitor alarm } \\
\text { shoot }\end{array}$ & $\begin{array}{l}\text { Perform the parameterization of the alarms by programming them properly. Watch } \\
\text { for alarms triggered and solve them quickly, minimizing stress and risks to the patient. }\end{array}$ & Bridi et al. ${ }^{28}$ \\
\hline \multicolumn{3}{|l|}{$\begin{array}{l}\text { Listen to the noise and alarm of } \\
\text { the devices }\end{array}$} \\
\hline \multirow[t]{3}{*}{ Do not have privacy } & Explain to patients the procedures that will be done; & Ministério da Saúde ${ }^{29}$ \\
\hline & Use of screens, close side curtains to ensure a reserved environment; & \\
\hline & $\begin{array}{l}\text { Minimally expose the body, discovering only the necessary parts and covering places } \\
\text { that do not need to be exposed, safeguarding the patient's privacy. }\end{array}$ & Baggio et al. ${ }^{30,31}$ \\
\hline
\end{tabular}

\section{Conclusion}

From this study, it can be concluded that, regardless of the patient's clinical situation, stress will always be present due to the multidimensionality involved in an ICU hospitalization, but that through simple and low-cost "humanizing" measures it is possible to minimize discomfort reported by patients, making hospitalization coping a smoother process.

Regarding the applied questionnaire, the authors evidenced as a factor making the questionnaire more difficult, since the patients reported anxiety in relation to the number of questions.

Thus, very similar questions could be associated, such as "listening for the alarm of the heart monitor to shoot" and "to listen to the alarm of the apparatuses". Among the stressors surveyed, "being annoyed" was the item reported by the patients as the most difficult to understand, and explanations are necessary due to the subjectivity of the question.

Another finding is the non-inclusion of other health professionals in the questions of the questionnaire, since some questions contemplate only two categories as "member of the nursing team does not present by name" or "nursing and doctors talking very loud", since several are the professionals who provide care to the patient, so the multidisciplinary team should be included in this context.

In an interview with a patient from the clinical ICU, the same authors found the presence of social networks in the intensive care setting, with the following report: "...they move on the cell phone all the time, whatsapp eating loose, every whistle, could at least silence it. "Thus, this is a factor that could be included in the questionnaire as a contextualization of the time lived.

In an interview with a patient from the clinical ICU, the authors found the presence of social networks in the intensive care setting, since the patient interviewed expressed discomfort with the use of cellular devices in this environment. Thus, this is a factor that could be included in the questionnaire as a contextualization of the current moment.

From this study, it is expected that its results will foster new research on the subject, contributing to increase the production of scientific knowledge and guide clinical practice.

Therefore, it is of paramount importance that the multiprofessional health team and, especially, the nurse, who plays a prominent role in patient care, be able to recognize the factors causing stress through a qualified listening, actions and strategies contemplated if making reference in this line of care, in addition to adopting measures that promote improvement of the quality of care provided.

\section{Acknowledgments}

None.

\section{Conflicts of interest}

The authors declare there is no conflicts of interest.

\section{References}

1. Padilha KG, Vattimo MFF, Silva SC, et al. Enfermagem em UTI: cuidando do paciente crítico. São Paulo: Manole; 2010.

2. https://www.portaleducacao.com.br/conteudo/artigos/enfermagem/ enfermagem-unidade-de-terapia-intensiva/52667

3. https://www.passeidireto.com/arquivo/50825402/brunner--suddarthtratado-de-enfermagem-medico-cirurgica-12-ed--ebook-pdf-smeltz

4. Tate JA, Devito Dabbs A, Hoffman LA, et al. Anxiety and agitation in mechanically ventilated patients. Qual Health Res. 2012;22(2):157-173.

5. Chen YJ, Jacobs WJ, Quan SF, et al. Psychophysiological determinants of repeated ventilator weaning failure: an explanatory model. Am J Crit Care. 2011;20(4):292-302. 
6. ht t p://ww w. s c i e lo.br/s c i e 1 o.ph p ? p id=S 0103 507X2013000300218\&script $=$ sci_abstract\&tlng=pt

7. h t t p://www.s cie 1 o.br/s c i e 1 o.php? pid=S 0080 62342010000300011\&script $=$ sci_abstract\&tlng=pt

8. ht t p ://ww w. s cie lo.br/s c i e 1 o.ph p ? p id=S 0103 $507 X 2007000100007 \&$ script $=$ sci_abstract\&tlng=pt

9. http://bvsms.saude.gov.br/bvs/publicacoes\%20/cadernos_humanizasus atencao_hospitalar.pdf

10. h t t p : / / w w w. s c i e 1 o.br/s c i e 1 o.p h p ? p i d = S 0034 $71672014000200306 \&$ script $=$ sci abstract

11. http://www.scielo.br/pdf/jbpsiq/v59n3/a03v59n3

12. http://scielo.isciii.es/pdf/eg/v12n32/pt_docencia1.pdf

13. Biancofiore G, Bindi ML, Romanelli AM, et al. Stress-inducing factors in ICUs: what liver transplant recipients experience and what caregivers perceive. Liver Transpl. 2005;11(8):967-972.

14. Knaus WA, Draper EA, Wagner DP, et al. APACHE II: a severity of disease classification system. Crit Care Med. 1985;13(10):818-829.

15. ht t p://ww w. s c i e lo.br/s c i e 1 o.ph p ? p id=S 0103 507X2015000100018\&script $=$ sci_abstract\&tlng $=\mathrm{pt}$

16. h t t p://w w w. s c i e lo.br/s c i e lo.php? pi d = S 0104 $11692006000500012 \& \mathrm{script}=\mathrm{sci}$ arttext\&tlng $=\mathrm{pt}$

17. https://repositorio.ucb.br/jspui/bitstream/10869/859/1/Bruna.pdf

18. https://revistas.ufpr.br/cogitare/article/viewFile/13108/8866

19. h t t p : / / w w w. s c i e 1 o.b r / s c i e lo.ph p ? p id = S 0104 07072010000200009\&script=sci_abstract\&tlng=pt
20. h t t p ://w w w. s c i e lo.br/s c i e lo.ph p s c ript=s ci arttext\&pid=S0100-69912005000600012

21. Aguilar-Nascimento JE. Como otimizar o preparo pré-operatório com terapia nutricional. Boletim SBNPE. 2010;12(32):2-5

22. h t t p://ww w. s c i e 1 o.b r/s c i e 1 o.ph p ? p id = S 0034 $70942009000500006 \&$ script $=$ sci_abstract\&tlng=pt

23. h t t p : / / w w w. s c i e lo.br/s c i e lo.ph p ? p id=S 0103 $21002012000400008 \&$ script $=$ sci_abstract\&tlng=pt

24. Puntillo K, Arai SR, Cooper BA, et al. A randomized clinical trial of an intervention to relieve thirst and dry mouth in intensive care unit patients. Intensive Care Med. 2014;40(9):1295-1302.

25. http://periodicos.pucminas.br/index.php/enfermagemrevista/article/ view/13020

26. https://www20.anvisa.gov.br/segurancadopaciente/index.php/ publicacoes/item/caderno-1-assistencia-segura-uma-reflexao-teoricaaplicada-a-pratica

27. Knobel, Elias. Terapia Intensiva: enfermagem. In: Almeida FP, Veloso JWN, Blaya RP, editors. Humanização em UTI. São Paulo: Editora Atheneu; 2006:39-48.

28. http://www.scielo.br/scielo.php?script=sci_arttext\&pid=S0103$507 \times 2014000100028$

29. http://bvsms.saude.gov.br/bvs/saudelegis/gm/2002/prt0019_03_01_2002. html

30. h t t p : // w w w. s c i e lo.br/s c i e lo.ph p ? pid = S 0034 $71672011000100004 \&$ script $=$ sci_abstract\&tlng=pt/

31. http://www.sbed.org.br/materias.php?cd_secao $=65$ 